University of Wollongong

Research Online

Faculty of Engineering and Information

Faculty of Engineering and Information

Sciences - Papers: Part A

Sciences

$1-1-2015$

The effects of vacuum annealing temperatures on the microstructure, mechanical properties and electrical resistivity of $\mathrm{Mg}-3 \mathrm{Al}-1 \mathrm{Zn}$ alloy ribbons

Fenghua Chen

University of Wollongong, phycfh@163.com

Qingxue Huang

Taiyuan University of Science and Technology

Zhengyi Jiang

University of Wollongong, jiang@uow.edu.au

Jingwei Zhao

University of Wollongong, jzhao@uow.edu.au

Binyu Sun

Taiyuan University of Science and Technology

See next page for additional authors

Follow this and additional works at: https://ro.uow.edu.au/eispapers

Part of the Engineering Commons, and the Science and Technology Studies Commons

Research Online is the open access institutional repository for the University of Wollongong. For further information contact the UOW Library: research-pubs@uow.edu.au 


\title{
The effects of vacuum annealing temperatures on the microstructure, mechanical properties and electrical resistivity of $\mathrm{Mg}-3 \mathrm{Al}-1 \mathrm{Zn}$ alloy ribbons
}

\begin{abstract}
This paper investigates the influence of vacuum annealing temperature on the microstructure, mechanical properties and electrical resistivity of Mg-3Al-1Zn rapid solidification (RS) magnesium ribbons. The results indicate that when the annealing temperature is increased, the grain size of the ribbons is dramatically reduced from 10 to $1 \mu \mathrm{m}$. The highest break stress and micro-hardness is obtained at $673 \mathrm{~K}$. These effects are ascribed to the dispersion strengthening caused by the high amount of fine nanoparticles distributed in the material. Electrical resistivity-temperature $(\rho-T)$ curves have been used to provide useful information about the effects of the annealing temperature on the grain size, grain orientation and crystal structure of the ribbons. In this way, a new lightweight electric wire or connection cable line could be produced which would have good electromagnetic interference (EMI).
\end{abstract}

\section{Keywords}

resistivity, mg, 3al, 1zn, effects, alloy, vacuum, ribbons, annealing, temperatures, microstructure, mechanical, properties, electrical

\section{Disciplines}

Engineering | Science and Technology Studies

\section{Publication Details}

Chen, F., Huang, Q., Jiang, Z., Zhao, J., Sun, B. \& Li, Y. (2015). The effects of vacuum annealing temperatures on the microstructure, mechanical properties and electrical resistivity of Mg-3Al-1Zn alloy ribbons. Vacuum, 115 80-84.

\section{Authors}

Fenghua Chen, Qingxue Huang, Zhengyi Jiang, Jingwei Zhao, Binyu Sun, and Yugui Li 


\title{
The Effects of vacuum annealing temperatures on the microstructure, mechanical properties and electrical resistivity of $\mathrm{Mg}-3 \mathrm{Al}-1 \mathrm{Zn}$ alloy ribbons
}

\author{
Fenghua Chen ${ }^{1,2,3}$, Qingxue Huang ${ }^{1 *}$, Zhengyi Jiang ${ }^{1,2}$, Jingwei Zhao ${ }^{2}$, Binyu Sun ${ }^{1}$, Yugui Li ${ }^{1}$ \\ 1) Heavy Machinery Engineering Research Center of Education Ministry, College of Mechanical \\ Engineering, Taiyuan University of Science and Technology, Taiyuan 030024, China \\ ${ }^{2)}$ School of Mechanical, Materials and Mechatronic Engineering, University of Wollongong, NSW 2522, \\ Australia \\ ${ }^{3)}$ Department of Physics, School of Applied Science, Taiyuan University of Science and Technology, \\ Taiyuan 030024, China
}

\begin{abstract}
This paper investigates the influence of vacuum annealing temperature on the microstructure, mechanical properties and electrical resistivity of $\mathrm{Mg}-3 \mathrm{Al}-1 \mathrm{Zn}$ rapid solidification (RS) magnesium ribbons. The results indicate that when the annealing temperature is increased, the grain size of the ribbons is dramatically reduced from 10 to $1 \mu \mathrm{m}$. The highest break stress and micro-hardness is obtained at $673 \mathrm{~K}$. These effects are ascribed to the dispersion strengthening caused by the high amount of fine nanoparticles distributed in the material. Electrical resistivitytemperature $(\rho-T)$ curves have been used to provide useful information about the effects of the annealing temperature on the grain size, grain orientation and crystal structure of the ribbons. In this way, a new lightweight electric wire or connection cable line could be produced which would have good electromagnetic interference (EMI).
\end{abstract}

\section{Keywords}

Magnesium alloys, AZ31, vacuum annealing temperature, mechanical properties, electrical resistivity

Magnesium (Mg), one of the lightest structural metal materials has the advantages of a good specific strength and stiffness ratio, easy damping, cutting, and recycling. Because of their low density and highly specific mechanical properties, Mg-based materials are often used by companies for light-weight applications such as in the aerospace and automotive industries [1]. However, a limited number of slip systems in $\mathrm{Mg}$ results in inadequate strengthening and in the

${ }^{*}$ Corresponding author: Qingxue Huang

Email address: qxhuang_pd@163.com 
degradation of ductility or deformability. Recent research into the formability of Mg-based alloys that involves the activation of alternative deformation mechanisms has been done for ultra-fine grained or even nanometer-scale materials [2-5]. RS is an opportunity to extend solid solubility, produce new phases and refine and homogenize microstructure, extending the solid solubility limits, etc. Magnesium alloy is easily oxidized, especially the ribbon easy combustion etc. RS makes full use of the advantage of the entire metal melting with eddy current energy in a vacuum so that impurities in the air can be prevented from entering into the magnesium and a high-quality alloy can be produced. While heat treatment in a vacuum environment can prevent oxidation and has a degassing effect which will further refine the grain structures. The fabrication of high-purity magnesium also uses a vacuum evaporation system and the $\mathrm{Mg}$ is then purified [6-8]. Hexagonal metals present a more complex case due to their low symmetry, which restricts the number of slip systems, and their strong plastic anisotropy. As for other use of vacuum treatment of magnesium, such as AZ31, AZ61, ZK60, ZE41 and AZ80 are mainly on the encouraging the corrosion resistance and vacuum diffusion bonding $[9,10,11,12]$.

The present research concentrates primarily on an annealing temperature of $573 \mathrm{~K}$ and lower. There are very few studies reporting annealing temperatures higher than $573 \mathrm{~K}$ for RS ribbons. However, for industrial-size material, the repeated roll casting reprocessing procedure requires a temperature above $723 \mathrm{~K}$ for approximately 10 hours $[13,14]$. Whether the higher annealing temperature can produce new phases and whether the refined and homogenized microstructure affects the mechanical properties are not yet clear. Until now, no particular relationship between vacuum annealing temperature, grain size and electrical resistivity has been reported $[15,16]$.

In the present work, the effects of the vacuum annealing temperature on the microstructure, the mechanical properties and the electrical resistivity of $\mathrm{Mg}-3 \mathrm{Al}-1 \mathrm{Zn}$ alloy ribbons at 573, 673 and $773 \mathrm{~K}$ are investigated. This study aims to obtain the annealing temperature on grain size, grain orientation, crystal structure, mechanical properties and electrical resistivity of the ribbons fabricated by RS. The nominal composition of the AZ31B alloy in weight percentage is $3.0 \% \mathrm{Al}$, $1.0 \% \mathrm{Zn}, 0.27 \% \mathrm{Mn}$ and the rest $\mathrm{Mg}$. The raw material of AZ31B was induction-melted in a quartz tube and melt-spun at a typical wheel surface speed of $30 \mathrm{~m} / \mathrm{s}$. Ribbons are vacuumannealed at the pressure of $2 \times 10^{-4} \mathrm{~Pa}$ with an elevated temperature of 573,673 and $773 \mathrm{~K}$ for $1 \mathrm{~h}$ and then cooled along with the vacuum furnace. The microstructure and cross-section of the ribbons were investigated by a field emission scanning electron microscope (FE-SEM, Hitachi 
S-4800) attached to an X-ray energy dispersive spectroscopy (EDS) setup. The crystal structure of the sample was analyzed using a Panalytical X'Pert PRO type X-ray diffractometer (XRD) with $\mathrm{Cu} K \alpha$ radiation. The Vickers hardness number (VHN) was determined using a microhardness test machine (HXP-1000TM). Indentations were made with a $100 \mathrm{gf}$ load applied for 15 seconds. Mechanical tests including break stress and elongation were performed at room temperature using an Instron-type tensile testing machine (Testometric M350-10KN, England) under a constant cross-head speed of $1 \mathrm{~mm} / \mathrm{min}$. The electrical resistivity of the ribbons was measured using a Quantum Design's multi-use vibrating sample VersaLab system. The temperature-dependent electrical resistivity $(\rho-T)$ curves were measured at a cooling/heating rate of $3 \mathrm{~K} / \mathrm{min}$ with four probe technique.

The room-temperature XRD patterns of AZ31B as-spun and annealed at temperatures of 573, 673 and $773 \mathrm{~K}$ for $1 \mathrm{~h}$ are presented in Fig. 1. It can be seen that the patterns can be indexed as a hexagonal close-packed structure, which indicates that the samples are in the $\alpha-\mathrm{Mg}$ phase at room temperature. No secondary phase $\left(\beta-\mathrm{Mg}_{17} \mathrm{Al}_{12}\right)$ is observed from the diffraction pattern. Because the solidification of ribbons is very fast (wheel speed $30 \mathrm{~m} / \mathrm{s}$ ), the $\beta-\mathrm{Mg}_{17} \mathrm{Al}_{12}$ phase does not have enough time to precipitate. According to the relationship between cooling rate and ribbon thickness $(\sim 40 \mu \mathrm{m})$, the cooling time is calculated to be about $1.20 \times 10^{-5} \mathrm{~s}$ and the cooling rate is about $5.8 \times 10^{7} \mathrm{~K} / \mathrm{s}$. As RS can greatly increase the solubility of $\mathrm{Al}$ in the $\alpha-\mathrm{Mg}$ phase, supersaturated solid solution AZ31B alloy ribbons are formed, and this can significantly improve the mechanical properties $[6,8,17,18]$.

The lattice parameters $(a, b, c), c / a$ and intensity ratio of $I_{(0002)} / I_{(10-11)}$ of the samples are calculated. The parameters $a$ and $c$, and the lattice parameter of the $c / a$ has been changed but not significantly. The intensity ratio of $I_{(0002)} / I_{(10-11)}$ is significantly influenced by the annealing temperature, however: 0.2558 (as-spun), $0.3104(573 \mathrm{~K}), 0.3518(673 \mathrm{~K})$ and 0.3250 (773 K). It is known that the basal plane orientation is very sensitive to the grain orientation and crystal structure, and the intensity ratio of $I_{(0002)} / I_{(10-11)}$ may also affect the mechanical properties of the magnesium ribbons $[12,17,18]$. 


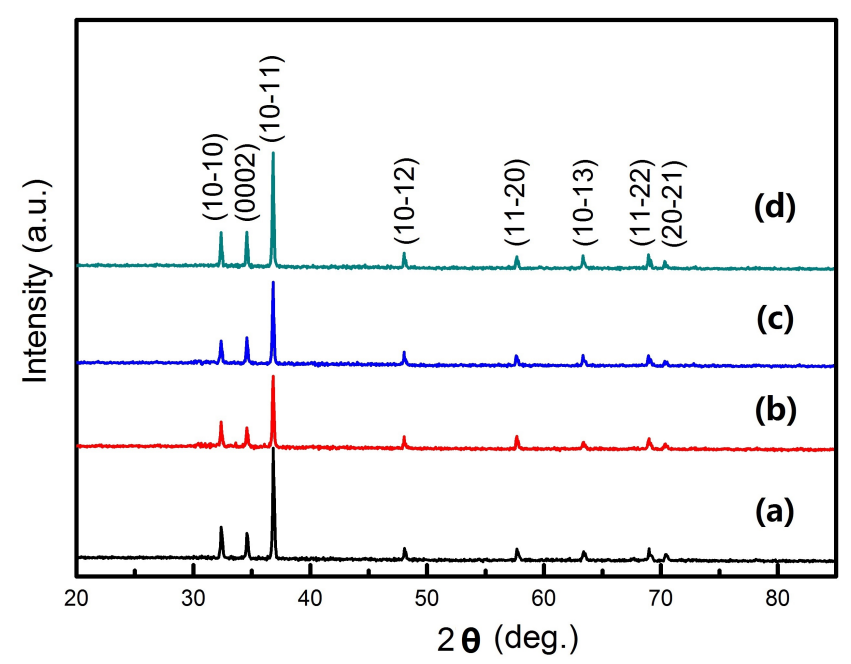

Fig. 1 Room-temperature XRD patterns of AZ31B (a) as-spun ribbon and vacuum annealed at (b) $573 \mathrm{~K}$, (c) $673 \mathrm{~K}$ and (d) $773 \mathrm{~K}$ for $1 \mathrm{~h}$.

The microstructure of the ribbons was investigated using FE-SEM. Figure 2 shows the typical FE-SEM micrographs of AZ31B as-spun ribbon and vacuum annealed at $673 \mathrm{~K}$ for $1 \mathrm{~h}$. As showed in Fig. 2(a), a typical dendrite crystal structure is observed under rapid cooling. Fig. 2(b) shows the microstructure of the as-spun ribbon's free surface. It is an equiaxial crystal structure with an average grain size of $5-10 \mu \mathrm{m}$, which is far below the grain size obtained by the conventional casting process. In RS conditions, the diffusion and migration of the solute atoms at the solid-liquid interface are hindered, leading to fast $\alpha-\mathrm{Mg}$ crystal growth and a high rate of solute rejection. In this way, a single supersaturated phase forms, which is significantly different from the conventional transformation of liquid $\rightarrow \alpha-\mathrm{Mg}+\beta-\mathrm{Mg}_{17} \mathrm{Al}_{12}$ [19-21]. Fig. 2(c) shows the typical micrographs of AZ31B ribbon annealed at $673 \mathrm{~K}$ for $1 \mathrm{~h}$. According to the XRD patterns, the samples are either still or in the $\alpha-\mathrm{Mg}$ state at room temperature. However, as shown in Fig. 2(c), the crystal structure with an average grain size of $0.5-1.0 \mu \mathrm{m}$ is far below the as-spun grain size. In Fig. 2(c) the ultra-grains with a grain size of about 20-50 nm are observed at the large $\alpha$ $\mathrm{Mg}$ grain surfaces and edges. Ordinary solidification of $\mathrm{Al}$ in magnesium is $11.5 \mathrm{wt} \%$, which is much higher than that of any original AZ31B contents, and it may be that no more $\mathrm{Al}$ atoms can precipitate. A regional point scan using EDS shows that the nanoparticles are of about $\mathrm{Zn}$ magnesium alloys, the $\mathrm{Zn}$ weight percentage is higher than the matrix [9]. The $\mathrm{Mg}_{0.97} \mathrm{Zn}_{0.03}$ phase 
has a relatively low melting point and will decompose at $623 \mathrm{~K}$. The phenomenon of the $\mathrm{Mg}_{3} \mathrm{YZn}_{6}$ phase on mechanical property enhancement has been reported on $\mathrm{Mg}-\mathrm{Zn}-\mathrm{Y}-\mathrm{Zr}$ alloys, and its transition temperature is about $720 \mathrm{~K}$. From Fig. 2(c), numerous small nanoparticles separated from the eutectic are homogeneously dispersed at the $\alpha$-Mg grain surfaces and edges. These particles contribute to the enhancement of material hardness [22-26].
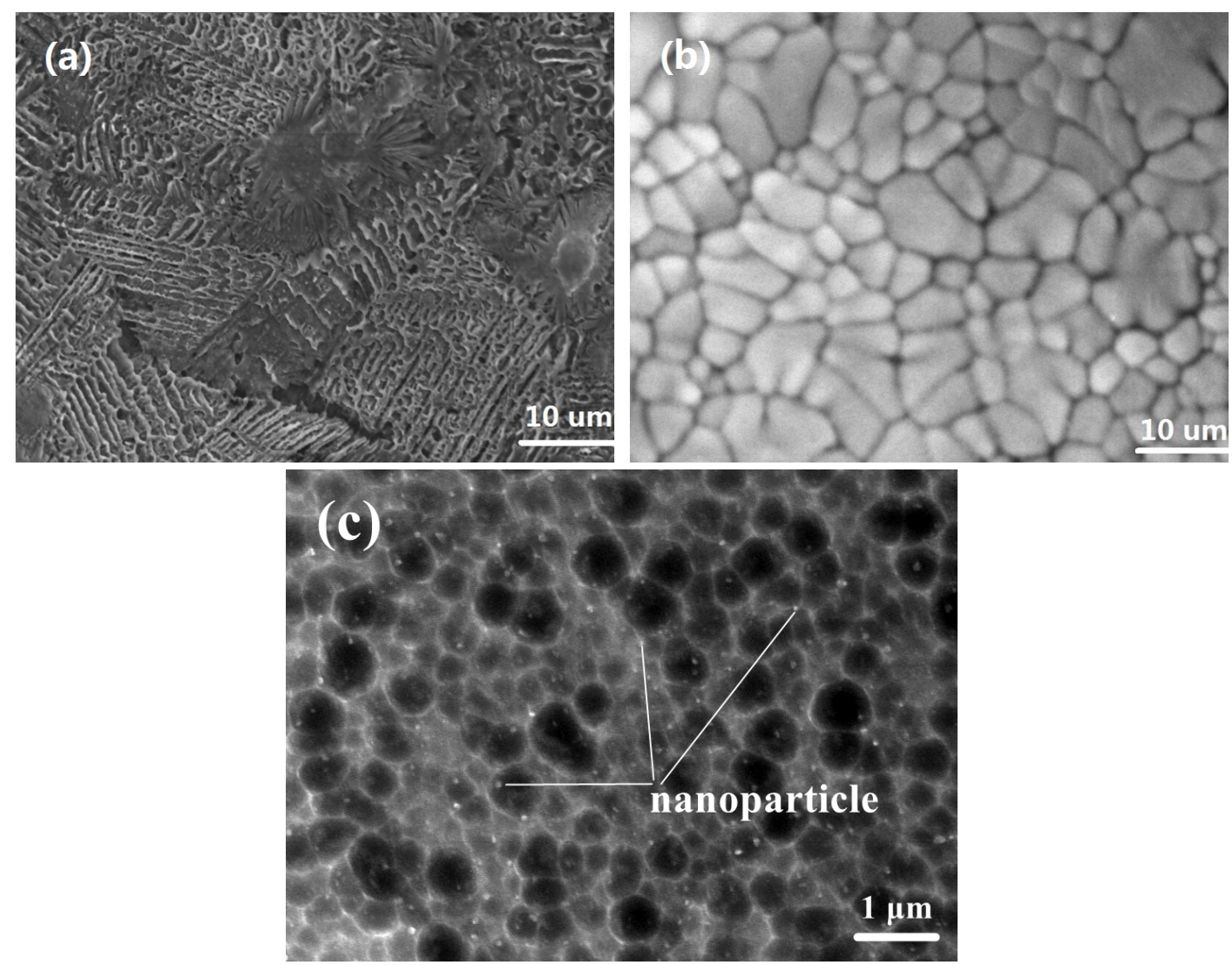

Fig. 2 FE-SEM micrographs of the different regions of AZ31B as-spun ribbon free surface (a), (b) and 673 $\mathrm{K}$ vacuum annealed (c)

The room temperature tensile properties of rapidly solidified ribbons are shown in Fig. 3. It can be seen that the tensile stress and strain vary as the annealed temperature increases. The ultimate tensile stress of the sample annealed at $673 \mathrm{~K}$ is about $203 \mathrm{MPa}$, which is much higher than that of the other different temperature annealed samples. The strain of the sample annealed at $673 \mathrm{~K}$ is about $3.8 \%$, which is half that of the as-spun ribbon. As the heat treatment temperature is increased up to $773 \mathrm{~K}$, the nanoparticle decomposes and as a result, both the tensile stress and strain change dramatically. While annealing temperature is increased from 673 to $773 \mathrm{~K}$, the tensile stress drops to $140 \mathrm{MPa}$ and the strain increases to $4.75 \%$. Annealing 
typically results in a soft, ductile metal that is easier to process. We can see that the elastic deformation region has gradually expanded as the annealing temperature increases. The elastic deformation region of as-spun ribbon is about $1 \%$ and annealing it at $573 \mathrm{~K}$ for $1 \mathrm{~h}$ increased the level to $1.5 \%$. The $773 \mathrm{~K}$ annealed ribbon finally reaches $2.5 \%$. The yield strength is defined as the $0.2 \%$ proof stress. The sample annealed at $773 \mathrm{~K}$ for $1 \mathrm{~h}$ shows an obvious discontinuous yield phenomenon with yield strength of about $25 \mathrm{MPa}$, which can significantly enhance the capability of elastic-plastic deformation of AZ31B alloy [27, 28].

The tensile fracture surface of the AZ31B, (a) as-spun and annealed at (b) $573 \mathrm{~K}$, (c) $673 \mathrm{~K}$ and (d) $773 \mathrm{~K}$ have also been examined. The as-spun ribbon mainly contains the typical dendrite and equiaxial crystal structure. The equiaxial crystal is a quasi-cleavage fracture with many tearing edges, which provide the evidence that many courses were completed and much energy was consumed before fracture. As for sample (c), the intensity ratio of $I_{(0002)} / I_{(10-11)}$ has had the maximum value. Plastic deformation is well known from the close-packed plane of the sliding desired maximum critical shear stress, in addition to the dislocation density and grain size, the crystallographic orientation also strongly influences the plastic deformation. This might be the reason why the mechanical properties of the ribbon tensile test dramatically changed for the sample annealed at $673 \mathrm{~K}$ for $1 \mathrm{~h}$. The increase in tensile stress can be ascribed to the critical stress for crack propagation at grain boundaries increasing as the grain size decreased. As for sample (d), grain refinements give rise to not only a good combination of high strength and high ductility at room temperatures, but also superplasticity. This indicates a tensile deformation regime, and a large number of cavities can be found. The cavities are mostly small and the majority of them are spherical. 

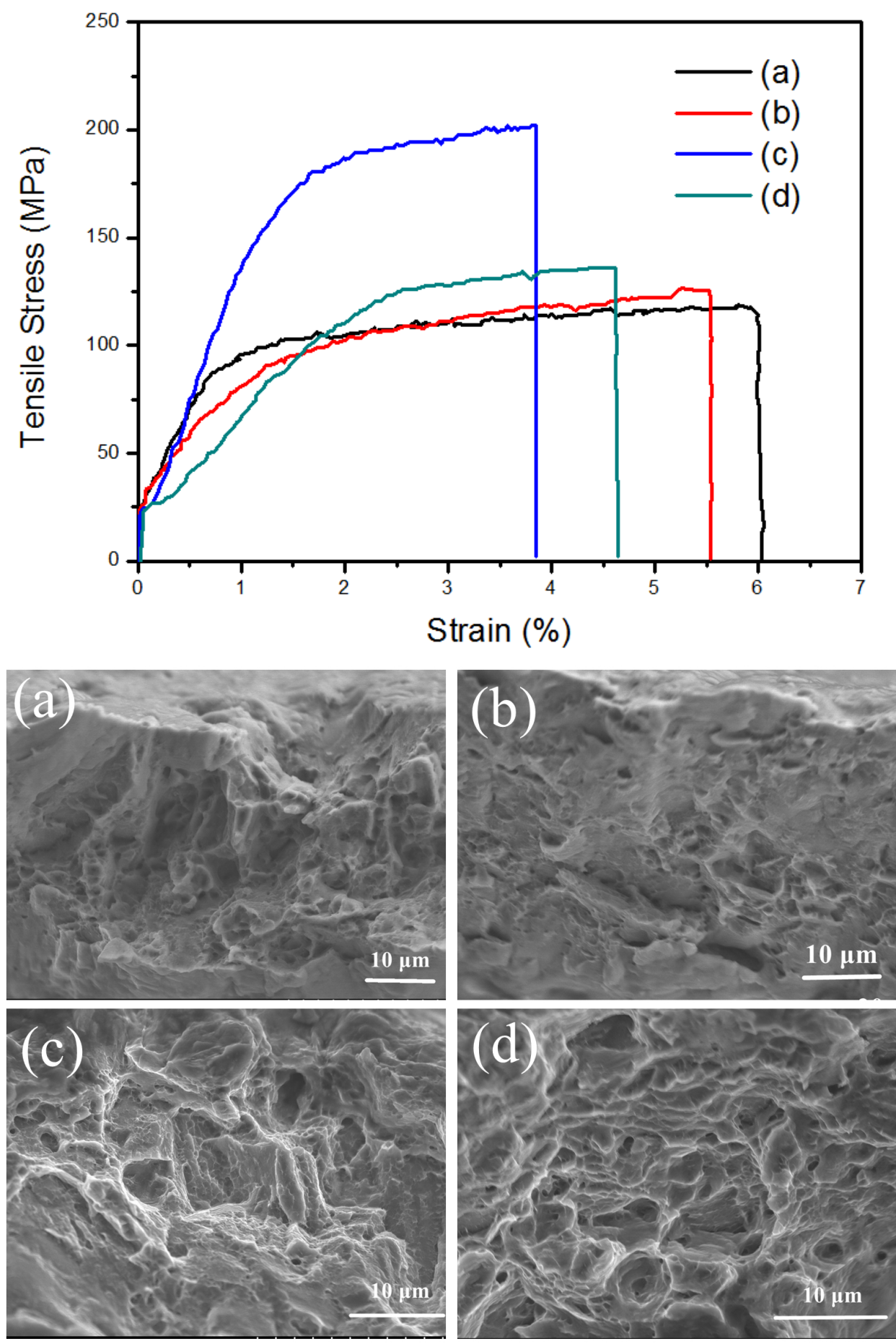

Fig. 3 Comparisons of the engineering stress-strain and fracture surface of four rapidly solidified AZ31B alloy ribbons, (a) as-spun ribbon and annealed at (b) $573 \mathrm{~K}$, (c) $673 \mathrm{~K}$ and (d) $773 \mathrm{~K}$ for $1 \mathrm{~h}$. 
Tensile stress and micro-hardness of the rapidly solidified AZ31B alloy ribbons can be seen in Fig. 4. It can also be seen that tensile stress shows a similar variation trend with micro-hardness. The specimen annealed at $673 \mathrm{~K}$ not only has the highest tensile stress but also the highest micro-hardness of about $150 \mathrm{HV}$. It has been reported that the micro hardness value of the quasicrystal phase is about $556 \mathrm{HV}$ and that of the $\beta-\mathrm{Mg}_{17} \mathrm{Al}_{12}$ phase is about $153 \mathrm{HV}$ [24]. High micro hardness can be achieved by adjusting the heat treatment temperature of the AZ31B alloy ribbon that contains the nanoparticles [22-24]. By grain refinement, a high micro hardness can be obtained which is twice the value of the ordinary casting state, even without modifying the phase in the magnesium alloy. The tensile stress and micro hardness of the alloys can be ascribed to the conjoint actions of:

(1) Fine grain size. Generally, the grain size of the material meets Hall-Petch relationship, that with the annealing temperature increase the garin size decreased and the ribbon have the better performance in tensile stress and microhardness [24].

(2) Solid solution strengthening. In this work the effect of solid solution strengthening by Al and $\mathrm{Zn}$ on the hardness of RS polycrystalline has been studied, with the annealing temperature increase the composition segregation reduced, and gets the good result.

(3) Dispersion strengthening from the presence of nanoparticles. As for sample (c), numerous small nanoparticles separated from the eutectic are homogeneously dispersed at the $\alpha$-Mg grain surfaces and edges. These particles contribute to the enhancement of material hardness.

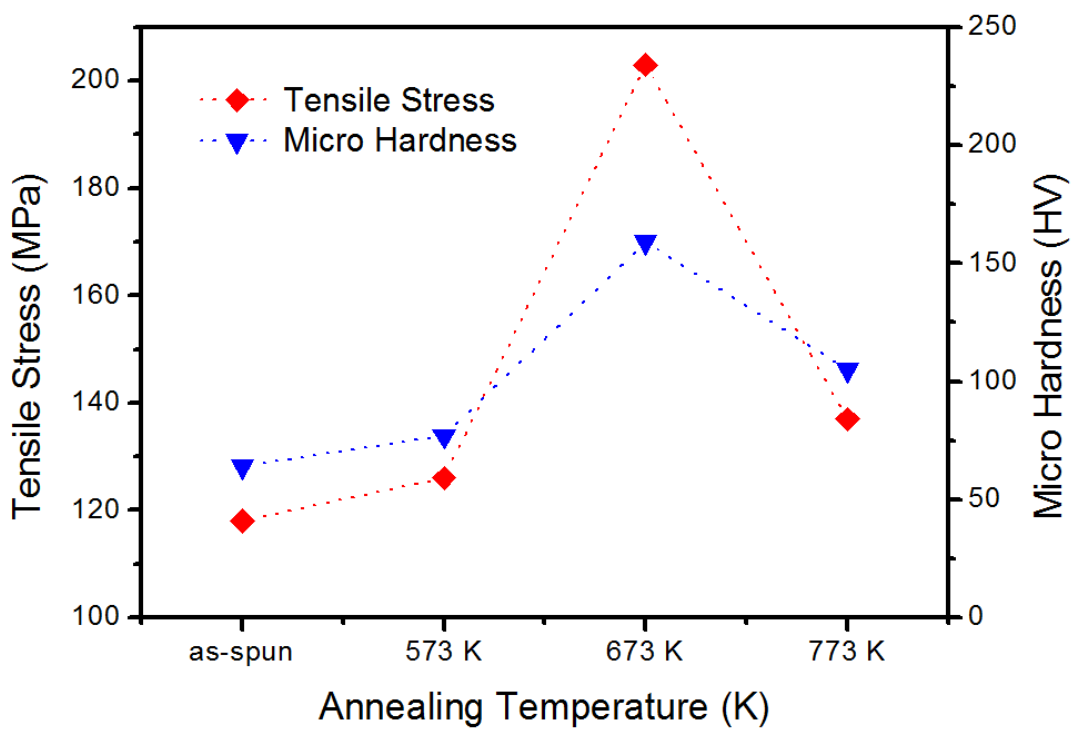

Fig. 4 The tensile stress and micro hardness of the rapidly solidified AZ31B alloy ribbons, as-spun ribbon and 
annealed at $573 \mathrm{~K}, 673 \mathrm{~K}$ and $773 \mathrm{~K}$ for $1 \mathrm{~h}$.

Figure 5 shows the temperature-dependent electrical resistivity $(\rho-T)$ curves of the AZ31B ribbons. Real magnesium alloy will always have crystal defects. For example, some points may not exist or may be held by other impurities. The electrical resistivity is a sensitive parameter which monitors the structural changes of the alloy. Thermal shock of the atoms in the lattice points will occur, and the thermal vibrations of the particles will appear as if phonons are moving in the crystal. Detailed analysis of the factors influencing the electrical resistivity can help explain the changes in the internal organizational structure of the alloy. The electrical resistivity decreases as the heat treatment temperature increases. In contrast to the sample resistivity in the as-spun and $573 \mathrm{~K}$ annealed sample, we can see that in the $573 \mathrm{~K}$ annealed sample, resistivity at the test temperature (above $225 \mathrm{~K}$ ) is higher than that of the as-spun sample. This might be due to the fact that the as-cast sample is better organised. At the same time, the $573 \mathrm{~K}$ heat treated sample will encounter more problems such as crystal defects and lattice mismatch. With the heat treatment at $673 \mathrm{~K}$ and above, alloy electrical resistivity decreases dramatically and approaches or reaches a resistivity of 61.9 nOmhs.m [15, 16, 29]. Further tests of the relationship between resistivity and temperature have been done. We can find that a well annealed magnesium alloy ribbon not only has excellent mechanical properties, but also a better relationship between temperature and electrical resistivity. The electrical resistivity-temperature curve shows that the magnesium ribbon could be a new and useful cryogenic temperature sensor. In this way, a new lightweight electric wire or connection cable line could be produced which would have good electromagnetic interference (EMI). 


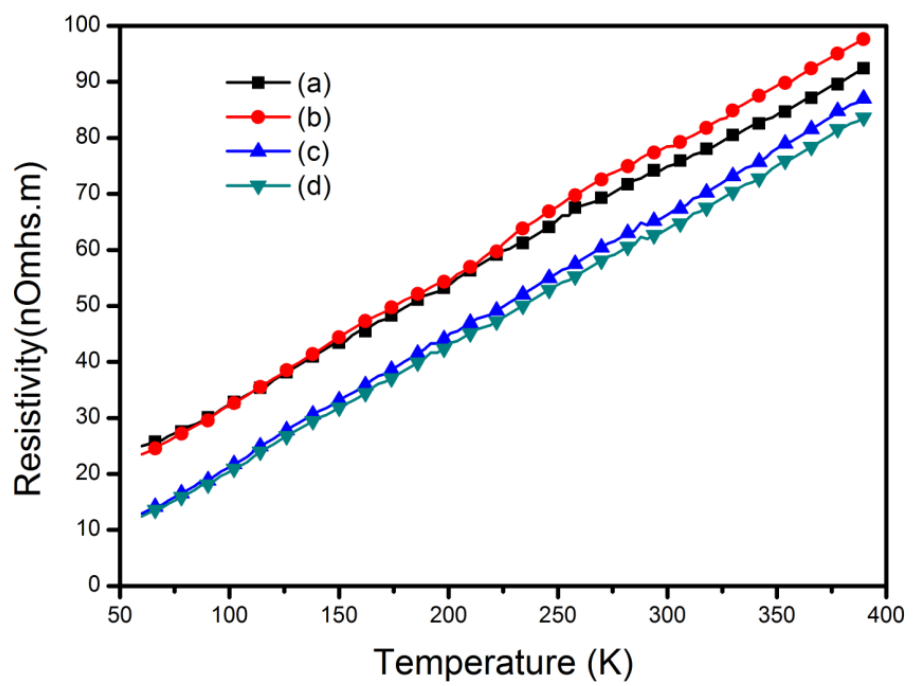

Fig. 5 The temperature-dependent electrical resistivity $(\rho-T)$ curves of the AZ31B, (a) as-spun ribbon and annealed at (b) $573 \mathrm{~K}$, (c) $673 \mathrm{~K}$ and (d) $773 \mathrm{~K}$ for $1 \mathrm{~h}$.

The present paper reports an experimental investigation of vacuum annealing temperature on the influence of rapid solidification of the microstructure, mechanical properties and electrical resistivity of nominal composition AZ31B magnesium alloy ribbons. It was observed that with an increase in the annealed temperature, the grain size of the ribbons dramatically decreased. The highest break stress and micro-hardness of the sample annealed at $673 \mathrm{~K}$ is ascribed to dispersion strengthening caused by the high amount of fine nanoparticles. The electrical resistivitytemperature curve was tested to understand the reason for annealing temperature's effect on the grain size, grain orientation and crystal structure of the ribbons. The electrical resistivity decreases dramatically and approaches or reaches a resistivity 61.9 nOmhs.m.

This work was supported by the National Key Basic Research Program of China (Grant No. 2012CB722801), Science and Technology Innovation Project of Shanxi Province of China (Grant No. 2013101013), National Natural Science Foundation of China (Grant No. 51375325), Postdoctoral research station Foundation of Taiyuan University of Science and Technology, China (Grant No.20142014).The author wishes to gratefully acknowledge the help of Dr. Madeleine Strong Cincotta in the final language editing of this paper.

\section{References}


[1] T. Sakai and H. Miura, InTechk, Rijeka (Croatia)2011, 219-244.

[2] Z. Trojanová, Z. Száraz, P. Palček, M. Chalupová., In: F. Czerwinski, (Ed), Intech, 2011,501-526.

[3] Govind, K. Suseelan Nair, M.C. Mittal, K. Lal, R. K. Mahanti, C. S.Sivaramakrishnan, Mater Sci Eng A 304, 2001,520-523.

[4] M. Mabuchi, M. Kobata, Y. Chino, et al., Mater Trans 44 (4), 2003, 436-439.

[5] A. Inoue, M. Matsushita, Y. Kawamura, K. Amiya, K. Hayashi, J. Koike., Mater Trans 43 (3), 2002,580584.

[6] F. Chen, M. Zhang, Y. Chai , C. Gong., Phys Status Solidi A 209 (8), 2012,1557-1561.

[7] M. Yu, Y. Wang and Y. Wang, Vacuum 83 (6), 2009, 980-983.

[8] Y. Tan, S. Ren, S. Shi, S. Wen, D. Jiang, W. Dong, et al., Vacuum 99, 2014, 272-276.

[9] X. Chen, J. Liu, Z. Zhang, F. Pan., Mater Des 42, 2012, 327-333.

[10] P.S. Feliu, A. Samaniego, V. Barranco, A. A. El-Hadad, I. Llorente, P. Adeva., Corros Sci 80, 2014, 461472.

[11] B. Song, S. Dong, Q. Liu, H. Liao, C. Coddet., Mater Des 54, 2014, 727-733.

[12] J.J. Bhattacharyya, S.R. Agnew and G. Muralidharan, Acta Mater 86, 2015,80-94.

[13] J. Cai, G.C. Ma, Z. Liu, H. F. Zhang, A. M. Wang, Z. Q. Hu., Mater Sci Eng A 456 (1), 2007, 364-367.

[14] H.T. Teng, T.J. Li, X.L. Zhang, Z.T. Zhang., T Nonferr Metal Soc 18, 2008,s86-s90.

[15] J.L. Nichols, J Appl Phys 26 (4), 2004, 470-472.

[16] R.S. Seth and S.B. Woods, Phys Rev B 2 (8), 1970, 2961.

[17] H.L. Zhao, S.K. Guan, F.Y. Zheng, Q.K. Li, L.G. Wang., T Nonferr Metal Soc 15 (1), 2005,144-148.

[18] F. Berge, L. Krüger and C. Ullrich, Mater Sci Eng A 614, 2014, 27-35.

[19] J.H. Zhang, Z. Leng, S.J. Liu, J.Q. Li, M.L. Zhang, W.R. Zhi., J Alloy Comp 509 (29), 2011, 7717-7722.

[20] P. Ghosh, M. Mezbahul-Islam and M. Medraj, Calphad 36, 2012, 28-43.

[21] R. Ma, X. Dong, S. Chen, Z. Pan, H. Ling, Z. Fan., Mater Sci Eng A 587, 2013, 328-335.

[22] X. Wang, W. Du, Z. Wang, K. Liu, S. Li., Mater Sci Eng A 530, 2011, 446-451.

[23] M.B. Yang, F.S. Pan, Z.S. Li, S. Jia., Chin J Nonferrous Metals 07, 2008,1191-1198.

[24] J. Zhang, H. Du, W. Liang, C. Xu, B. Lu., J Alloy Comp 427 (1), 2007, 244-250.

[25] J. Zhang, L. Pei, H. Du, W. Liang, C. Xu, B. Lu., J Alloy Comp 453 (1), 2008, 309-315.

[26] H. Asgharzadeh, E.Y. Yoon, H.J. Chae, T. S. Kim , J. W. Lee, H. S. Kim., J Alloy Comp 586, 2014,S95S100.

[27] Z. Pu, G.L. Song, S. Yang, J. C. Outeiro, O. W. Dillon, D. A. Puleo, et al., Corros Sci 57, 2012, 192-201.

[28] I. Polmear, J Mater Sci Tech-Lond 10 (1), 1994, 1-16. 
[29] J. Seymour, Pitman, 1972. 